\title{
Damages Caused by Natural Disasters and the Number of Natural Calamities' Effect on Philippine Government's Spending on Disaster Management
}

\author{
Tricia Ann Rhemae A. Cunanan 1*iD, Ediana Frances L. Lagasca² (D), \\ Christine Janelle J. Noriega ${ }^{3}$ (D), Ronaldo R. Cabauatan 4 (i)
}

${ }^{1}$ College of Commerce and Business Administration, University of Santo Tomas, Manila, Philippines. Email: triciaann.cunanan.comm@ust.edu.ph

${ }^{2}$ College of Commerce and Business Administration, University of Santo Tomas, Manila, Philippines. Email: edianafrances.lagasca.comm@ust.edu.ph

${ }^{3}$ College of Commerce and Business Administration, University of Santo Tomas, Manila, Philippines.

Email: christinejanelle.noriega.comm@ust.edu.ph

${ }^{4}$ College of Commerce and Business Administration, University of Santo Tomas, Manila, Philippines;

Research Center for Social Sciences and Education, University of Santo Tomas, Manila, Philippines;

The Graduate School, University of Santo Tomas, Manila, Philippines;

Social Sciences Division, National Research Council of the Philippines, Philippines.

Email: rrcabauatan@ust.edu.ph

\section{CORRESPONDING \\ AUTHOR (*): \\ Tricia Ann Rhemae A. Cunanan \\ (triciaann.cunanan.comm@ust.edu.ph)}

\section{KEYWORDS:}

Natural disaster

Disaster management

Spending

Healthcare

\section{CITATION:}

Tricia, A. R. A. C. et al. (2022). Damages

Caused by Natural Disasters and the

Number of Natural Calamities' Effect on

Philippine Government's Spending on

Disaster Management. Malaysian Journal of

Social Sciences and Humanities (MJSSH),

7(2), e001284.

https://doi.org/10.47405/mjssh.v7i2.1284

\begin{abstract}
This study examines the relationship between the damages caused by natural disasters and the Philippine government's spending on disaster management and healthcare, especially that despite the country's exposure to natural disasters, the Philippine government significantly decreased its disaster funds for the 2020 national budget. Several studies have concluded that most of the local government units in the Philippines were evaluated as only 'partially prepared' when it comes to disaster preparedness. As part of the Pacific Ring of Fire, an average of 7.5 typhoons and increased exposure to earthquakes are experienced in the Philippines annually, which should make public spending on disaster management and healthcare a national priority. Results show that disaster management expenditure and economic losses are positively related, while no relationship exists between disaster management expenditure, and deaths and exposure. Meanwhile, healthcare spending and deaths are negatively related, healthcare spending and economic damages are positively related, and healthcare spending and exposure have no relationship.
\end{abstract}

Contribution/Originality: This study is one of the few that investigated the relationship between government's disaster management and healthcare spending as dependents of exposure to natural disasters, deaths, and amount of damage caused by such. The paper's primary contribution includes comprehensive data that can aid government's decision-making and formulation of fiscal policies. 


\section{Introduction}

With an average of 7.5 typhoons making landfall in the Philippines annually since 1970, the country is considered to be one of the most prone countries to tropical storms in the world (Strobl, 2019), the intensity of tropical cyclones are expected to worsen as the world faces the adverse effects of rapid climate change (Knutson et al., 2010; Emanuel, 2013) those that are historically relatively less affected by disasters are now more likely to deal with such extreme hazards (Alcayna et al., 2016). According to the International Disaster Database, storms and earthquakes were among the most frequently occurring natural disasters in the Philippines from 1990 to 2014 - storms causing the most number of deaths and greatest economic losses (Wannewitz et al., 2016). The frequency of the occurrence of natural disasters like tropical cyclones and earthquakes in the Philippines can be attributed to the country's geographic location. The Philippines is located in the Pacific Ring of Fire where two major tectonic plates - Pacific and Eurasian, meet, therefore increasing the risk of earthquakes for the country. Several locations along the Manila Trench and Philippine Subduction Zone are named as areas to have a higher probability of generating major earthquakes - such areas include Manila and Davao (Pailoplee \& Boonchaluay, 2016). The country experiences an average of 20 earthquakes daily, damaging earthquakes have also been recorded due to numerous fault lines (Baquiran et al., 2017). Tropical cyclones and earthquakes cause secondary phenomena like flooding, landslides, heavy monsoon rains, and drought (Doroteo, 2015) which resulted in the destruction of human lives and livelihood.

Natural disasters that occurred between 2000 and 2016 in the Philippines caused more than 23,000 lives and affected an estimate of 125 million individuals; the associated socioeconomic damages brought about by these natural disasters was approximately USD 20 billion in total with an average of USD 1.2 billion damages yearly (Jha et al., 2018). Typhoon Yolanda, with an international name Haiyan, affected 16 million individuals in 14 separate provinces in the Philippines, resulting in 6,293 fatalities; given that the super typhoon landed and traversed through Metropolitan Manila, the damages would have been 2.5 times greater (Villacin, 2017). Despite the growth in the country's Current Health Expenditure (CHE) and an increase in Philippine Health Insurance Corporation (PhilHealth), the country's national health insurer, coverage from $75 \%$ population coverage in 2012 to 89\% in 2015, and 92\% in 2016 (Dayrit et al., 2018), government schemes and compulsory contributory health care financing schemes consistently only ranks second in terms of its share on CHE by financing scheme; household-out-of pocket payment still holds the highest share with more than half, 54.2\%, in 2016. Government schemes and compulsory contributory health care financing schemes are those financing schemes whose (1) population coverage is automatic and/or universal for all citizens and (2) contribution payment is mandated by law for all the population or for specific groups within the population, like social health insurance or compulsory private insurance (OECD, 2011). Population coverage rate is the total number of PhilHealth members and their dependent ratios to the country's population for the year being accounted for (Dayrit et al., 2018).

From a total number of reported deaths of 8,520 in the years 1994 to 2014, the number more than doubled to 19,793 casualties from 2004 to 2014 . This may be caused by the doubling of the occurrence of natural calamities, the growing population, and other risk factors (Doroteo, 2015). The National Disaster Risk Reduction Management Fund (NDRRMF) is a major mechanism of the government in financing recovery and reconstruction.; although the financial allocation for NDRRM Fund has seen a steady 
increase in the past years, from 2016 to 2017 where a more than half decrease in the PHP 38.9 billion budget in 2016 to PHP 15.8 billion in 2017 was observed (Villacin, 2017).

Disastrous natural calamities have been gaining recognition for being a catalyst for political action and policy changes (Pelling \& Dill, 2009). Governments might choose not to allocate a certain portion of their national budget for disasters because it is hard to predict (Phaup \& Kirschner, 2010). According to Gaiha et al. (2012), the pay-off of learning from past disaster experiences is high as long as the government does not suffer from the Samaritan Dilemma. Developing countries experience relatively higher deaths and more severe damages during disasters yet these are the same countries that make fewer efforts to counteract such adverse impacts. However, there is little emphasis on its importance due to the methodological difficulties in determining the impacts of events (Benson, 1997). It also has placed a continual and fluctuating burden on government finance to meet the cost of public prevention and preparedness measures to fund the programs for disaster management (Benson, 1997). With that being said, the objectives of this study were the following: (1) evaluate the relationship of deaths and amount of damages caused by natural disasters and the number of natural calamities per year to the government's expenditure on disaster management and healthcare, (2) identify other factors that may affect the government's expenditure on healthcare and disaster management, and (3) provide insights and recommendations that may aid in the policymaking of the government.

Jha et al. (2018)emphasized that natural disasters inflict suffering on local populations and life-threatening conditions for the poor. However, these natural disasters also give an opportunity to local authorities to upgrade capital stock, adopt new technologies, enhance risk-resiliency, and raise standards of living due to reallocation of budget and foreign donations. This was adapted from the hypothesis introduced by Schumpeter (1962) called "creative destruction" wherein long-standing arrangements and assumptions must be destroyed to pave way for new resources and innovation. Municipal governments in the Philippines mitigated the impact of natural disasters by allocating more fiscal resources to build local resilience while utilizing additional funds provided by the national government for rehabilitation and reconstruction.

This paper contributed to the existing work in the area of resource allocation, disaster management, health care, and the like, particularly in the Philippines. Previous studies such as those conducted by Bredenkamp and Buisman (2016) and Obermann et al. (2018) focused on disaster preparedness and healthcare expenditure, both public and private. Furthermore, the motivation for this study came down to a lack of existing studies, past researches primarily focused on economic results, especially economic growth. There are limited studies that examine the relationship between public health spending, death toll, and the amount of damages caused by natural disasters to government expenditure on disaster management as a potential factor in determining policymaking and adjustments. Thus, this study made an important contribution as it provided significant information that would help the government in fiscal policymaking for an improved outcome.

\section{Literature Review}

\subsection{Exposure, Disaster Management, and Healthcare}

Howe and Bang (2017) investigated the impact of the gravest natural disasters in contemporary Asian history which happened to be Typhoon Yolanda in the Philippines 
and Cyclone Nargis in Myanmar, both causing thousands of deaths and millions worth of damages. The study focused on the responsibility of the national government in terms of natural risk disaster management, and it has been found that the national resilience and government preparedness to reduce the adverse impact of natural disasters in both countries were insufficient despite being regularly exposed to typhoons and tropical storms.

A theoretical model by Cohen and Werker (2008) states that the availability of ex-post relief can affect the balance between ex-ante protection and ex-post relief. Buchanan (1972) coined the term Samaritan's Dilemma to show that altruism can result in adverse behavior of the beneficiary due to the failed effort of the benefactor to act properly. Foreign aid can have negative and positive effects - if fungibility and crowding-out effects outweigh possible preventive effects, foreign aids from the past will lead to relatively higher deaths because it decreases incentives in providing protective measures (Raschky \& Schwindt, 2016). Results of this study indicate that major storm events show that an increased level of previous foreign aids increases mortality rates while the probability of a non-zero death is increased for floods and major earthquakes due to foreign aid.

Baquiran et al. (2017) assessed the effectiveness of disaster preparedness of highly vulnerable barangays in Metro Manila along the West Valley Fault using the Disaster Preparedness Audit - results show that none of the barangays assessed could fulfill the 27 criteria on prevention and mitigation, response, and rehabilitation, and recovery for disaster preparedness. Most of the barangays were only able to satisfy $50-74 \%$ of the criteria. The study emphasizes that a direct relationship can be observed between the prevalence of a natural event and disaster preparedness. The less often a natural event occurs in the country or specific area, the less likely disaster managers prepare. Dariagan, Atando and Asis (2020) also assessed the effectiveness of disaster preparedness to natural hazards of 92 profiled municipalities in the central Philippines with an initial population of 2.4 million people. The results suggest that local government units were highly vulnerable to tropical cyclones, floods, earthquakes, and landslides, and these are due to the poor database management, insufficient manpower, and diverse attitude of stakeholders. Because of the Philippine Risk Reduction and Management Act of 2010, all municipalities have functional offices for risk management. However, they did not meet the requirements and relief functions as they are only 'partially prepared' on the criteria of System \& Structures and Policies \& Plans. Regarding Building Competencies criteria, municipalities were also rated as 'partially prepared' as they failed to build partnerships with other organizations and organize training, audit on infrastructures, and media management. LGUs had a good rating in Equipment and Supplies, the 4th criteria on the assessment, as it was from the result of reforms from the aforementioned Republic Act. It showed that government funds allotted to professional development were misallocated. It was mentioned in the Philippine Disaster Risk Reduction Management (DRRM) Act of 2010 that the local government units must allot $5 \%$ of their budget as a calamity fund. Seventy percent must go for disaster preparedness measures while $30 \%$ is for response and recovery. For the past decade, it has shown that only $30 \%$ are possibly spent for disaster preparation across most cities and municipalities and if the disaster is not catastrophic in a tremendous sense, $70 \%$ of the calamity fund will be reallocated to other projects or fund bonuses for government employees.

Chacko et al. (2019) emphasized the optimal disaster response with the phases of emergency management that includes mitigation, preparedness, response and recovery. When disasters occur, the local government must be the one to initiate a response through 
the incident command system, activation of local emergency management plan and mutual aid agreements and setting up of an emergency operations center. Alert systems from the local government units are critical to inform personnel and the public about weather conditions, evacuation orders, road closures, and healthcare facilities. Balgos (2013) discussed how Typhoon Ondoy in 2009 and habagat in 2012 showed the poorness and ineffectiveness of disaster management of the country. After the aforementioned catastrophic events, it led to legislation enactment in relation to disaster risk reduction and climate change adaptation. The study argues that community-based disaster risk reduction and management must be calibrated and scaled-down at the local level to guarantee community resilience, safety, and sustainable development.

As Gaiha et al. (2012) initiated the concept of combining learnings from past experiences and increasing resources for disaster prevention towards reduction of disaster-related damages, Dangcalan et al. (2019) showed how Marikina City evolved its disaster risk management systems and strengthened its local institution. Despite the challenges faced by the Marikina City Disaster Risk Reduction and Management Office (MCDRRMO) including legislation limitations, lack of funding, limited access to new technology, the Office is still an example of how disaster risk management structures can be institutionalized at the local level. The study also concluded that the country has a 'reactive' disaster management system, and its policies have a top-down centralized approach, meaning the national government usually addresses the needs of every local government unit in times of disaster.

In the context of healthcare, Salazar et al. (2016) focused on the post-disaster health impact of natural hazards in the Philippines in 2013 when 5 floods, 8 tropical cyclones, and 1 earthquake took place. The World Health Organization created a tool called Surveillance for Post Extreme Emergencies and Disasters (SPEED) which provides realtime syndromic surveillance during emergencies and natural disasters that allows early detection and monitoring of disease trends. SPEED was activated during the following major natural disaster events: Luzon Flood, Bohol Earthquake, and Typhoon Yolanda. It has been found that these types of natural disasters may increase both communicable and non-communicable diseases, as well as vector-borne diseases due to an increased influx of water through rain and storm surges. Disease surveillance can help government officials in decision-making on the disaster response, preparedness, and recovery phases. It has been found that communicable diseases were the most commonly observed for all three disasters and this is due to health system vulnerability and disruption of basic needs. It also showed that common disaster syndromes correlate with the country's morbidity profile. These common disaster syndromes can be reduced by efforts of prevention, response, and recovery by the responsible authorities. The rates of diseases during natural disasters depend on the scale of disruption of health systems, therefore, decision-makers must allocate budget, plan logistics, and human resources for future disasters.

Bredenkamp and Buisman (2016) assessed the progress of the Philippines in providing financial protection in the health sector, it was measured by the estimates of health insurance coverage, out-of-pocket spending, catastrophic payments, and impoverishing health expenditures. Results of the surveys conducted in 2000 and 2013 mainly focus on health spending across the respondents is medicines and there is an increase of $150 \%$ from year 2000 to 2012 on out-of-pocket spending which pushed more than 1.5 million Filipinos into poverty. Catastrophic payments tripled from $2.5 \%$ to $7.7 \%$ since 2000 . These catastrophic payments are made when a household's financial obligations to the 
healthcare system exceed $40 \%$ of the remaining income after essential needs are met. It typically happens when healthcare spending reaches a certain level, putting a person in financial distress. The findings of the study conclude that the Philippines is able to keep up with other Asian middle-income countries in terms of protecting households against the financial consequences of health spending and put itself on the right path to reach the Universal Health Care goal of financial risk protection. It was reported that in 2008, Filipinos experienced struggle in getting financial resources for medical treatments and $56 \%$ of households also struggled from distant health facilities. The study recommends that health insurance agencies like Philippine Health Insurance Corporation or also known as PhilHealth will continue to reform how it pays providers and efforts in ensuring the benefits coverage and eligibility will be covered.

According to Ray et al. (2013), although all countries are affected by disasters, major impacts are felt by low-income countries where $86 \%$ of deaths are due to flooding. A sustained increase in the occurrence of natural disasters in the past decade has been observed especially in the regions of South Asia, South-East Asia, and Africa. Although the World Bank classified the Philippines to be a lower-middle-income country, flooding is considered to be a common secondary phenomenon brought about by its extreme exposure to tropical cyclones; disasters, may it be natural or man-made, have long and short-term impacts on healthcare and resilience. Immediate effects of disasters include increased mortality and morbidity rates accompanied by an increase in the incidence of injuries, toxic exposure, diseases, and mental health problems. Aside from these, natural calamities can also have adverse effects on nutrition, education, health, income generation and to the recovery of human and physical assets. According to Mercado (2016) who conducted a study on the risk perceptions and responses to climate change and natural disasters of people living in BASECO compound, the poor are the most hurt in the occurrence of natural disasters because of the substandard resources the poor have access to, which can be observed in the quality of their housing; low-income housing is commonly located where there is a higher risk of disasters, like BASECO compound. Mercado (2016) concluded the following: (1) the residents' awareness of climate change and disaster risks positively impacts self-efficacy, distress, risk perception, concern, responsibility, resilience, and adaptive capacity, (2) distress has a negative impact on resilience, (3) high risk and perception may not be sufficient to increase the residents' adaptive capacity and lastly (4) out of the eight variables, resilience has the weakest response which suggests a challenging recovery for the residents in BASECO with their savings alone after the occurrence of natural calamities.

Wenzel and Wolf (2013) focused on the effects and possible ways of managing the risks and uncertainties catastrophic events present and classified catastrophes into two (2): man-made and natural. What separates one from the other is the countermeasures each one requires, but the nature of damage the two can cause does not differ significantly. According to Wenzel and Wolf (2013), there are three (3) kinds of effects that result from catastrophic events. These are direct effects of physical destruction and losses of human life, indirect short-term effects or the supply chain disruptions and recovery measures, and indirect long-term effects or the impact on investment decisions. From a macroeconomic perspective, the loss of physical capital would mean a decrease in the country's production capacity as well. In trying to measure the consequences of the reduced econroseomic productivity, monetary value must be placed upon the resources that were destroyed. Given such a situation, other indirect methods of measurements can be used (Rose, 2004). The economic assessment of human life is even more challenging, but during the attack in New York on September 11, 2001, Bram et al. (2002) calculated 
the loss of total earnings of all the victims by adding their current incomes until they would have retired. It resulted in an estimated 7.8 billion USD of lost human capital. The common findings amongst the past researches and academic papers stated in this study of Wenzel and Wolf (2013) is that the GDP per capita and death toll from natural disasters have an inverse relationship. Richer countries can better afford to delegate their resources for protective measures and rescue operations in relation to natural disasters, hence lowering the numbers of fatalities (Wenzel \& Wolf, 2013).

Aside from economic development, findings of other studies have presented several other possible factors that may determine a natural disasters' impact on a certain country. These are the role of institutions (Kahn, 2005), government stability (Raschky, 2008), educational attainment (Skidmore \& Toya, 2007), and economic inequality (Anbarci et al., 2005). Anttila-Hughes and Hsiang (2013), studied the post-disaster losses caused by natural disasters and found that a better understanding of post-disaster economic outcomes is important because it helps in the formulation of new policies and institutions; if most of the damages manifest post-disaster, programs and other interventions might need a revisit, and for the improved understanding of the possible long-term effects of the disaster. They were able to conclude that for the average household, an estimate of $94 \%$ of the economic loss due to disaster comes from unearned income long after the occurrence of the disaster (Anttila-Hughes \& Hsiang, 2013). On the contrary, Ferreira et al. (2013) studied the impact of development on casualties caused by natural disasters, particularly floods, in 92 countries from 1985 to 2008 and found that income does have a significant, indirect impact on fatalities through the improvement of flood frequency and magnitude. However, this was seen to be inconsistent and can only be observed in lowerincome countries; evidence, although minimal, correlating governance and flood fatalities have been found (Ferreira et al., 2013).

\subsection{Deaths, Disaster Management and Healthcare}

Heijink et al. (2012) and Budhdeo et al. (2015) conducted a study on western countries while Ahmad and Hasan (2016) and Rahman et al. (2018) based their study on South-East Asia. In western countries, an average of 2.6-5.3\% annual decline of avoidable mortality was observed, simultaneous to the rise of cross-country healthcare spending of 1.9 to 5.9\% annually (Heijink et al., 2012); for countries in the European Union, a 1\% decrease in government's healthcare expenditure resulted to a 0.1217 increase in neonatal mortality, 0.0499 in postneonatal mortality, 0.0185 in one to five years of age mortality, 0.1897 in under five years of age mortality, 2.5398 for adult male mortality, and a 1.4492, increase in adult female mortality (Budhdeo et al., 2015). Ahmad and Hasan (2016) conducted a study in Malaysia that investigated the relationship between government expenditure, governance, and health outcomes. The study found that there is a stable relationship between life expectancy and its determinants: income level, public health expenditure, corruption, and government stability. Rahman et al. (2018) were able to conclude that countries in the South Asian Association for Regional Cooperation and Association of South-East Asian Nations (SAARC-ASEAN) have relatively lower healthcare expenditure compared to nations belonging to the Organisation for Economic CoOperation and Development (OECD). It has been found that healthcare spending - public, private, and total healthcare spending, improve the health outcomes namely life expectancy at birth, crude death rate, and infant mortality rate in each region. It recommends an increase in healthcare spending for the countries in the SAARC-ASEAN in order to improve mortality rates. 
The difference between these studies conducted by Heijink et al. (2012), Budhdeo et al. (2015), Ahmad and Hasan (2016), and Rahman et al. (2018) and this research is that this research will focus on mortalities caused by natural disasters and deaths is a determinant of healthcare expenditure.

In assessing the long-term damages, Wenzel and Wolf (2013) used 30 years' worth of macro-level data from different disasters according to income groups and it has been found that low-income groups suffered damages larger than their assets, suggesting that those who are in the lower bracket of the income groups are hurt most when natural calamities occur. Although attempts were made by governments to increase their healthcare expenditure with the goal of improving their countries' health conditions, the availability of budget has been a challenge especially for low-income countries. Because of the limited financial resources, the focus has been on disaster recovery and less for building resilient primary healthcare. The study claims that disaster is the result of the interaction between the hazard and the vulnerability of those who are affected, and not on the occurrence of hazard alone. It was also emphasized the importance of conducive healthcare facilities that can efficiently perform medical disaster response given that primary healthcare facilities are the first contact between an individual and health care in times of critical need. Proper government intervention, including resource allocation, is needed in order to make sure that the primary healthcare, both at the national and local levels, are resilient and prepared to address disaster-related situations.

The concept of Universal Health Care (UHC) has gained attention especially in low and middle-income countries and has become a priority policy goal among many countries. (Obermann et al., 2018). With the primary objective of analyzing the role of Philippine National Health Insurance (NHI) in achieving UHC and the possible challenges and areas of improvement, according to this paper, in 2014, the Philippines has one of the highest out-of-pocket healthcare expenditures of 54\% among its neighboring countries like Indonesia, Thailand, and Vietnam. PhilHealth, the country's national health insurer, is tasked to improve access to quality healthcare and reduce out-of-pocket expenditures. Financial risk protection is one of the major goals of UHC and the massive growth of PhilHealth payments from PhP 17.1 billion in 2006 to PHP 101.8 billion in 2016 is because of the doubling of the subsidy payments made for the poorer households. However, due to the simultaneous increase in population, inflation, and total health expenditures, this leap in the subsidies paid by PhilHealth has been offset from $11 \%$ to only $14 \%$ share in the country's Total Health Expenditure. In 2018, an estimated 93 million out of 104 million Filipinos are covered by PhilHealth. The remaining 11 million individuals are those who are near-poor, non-registered formal sector workers, self-employed professionals, and inmates. To further extend the coverage of PhilHealth, a revenue source similar to Sin Tax is needed. According to Ray et al. (2013) those who are in the low bracket of the income groups are the most vulnerable to the major impacts of natural hazards. Thus, emphasizing the need to extend PhilHealth's coverage to the poor and to anyone with greater need of assistance. Aranas et al. (2020) studied the importance of microfinancing in the Philippines and found that microfinancing plays a significant role in the improvement of poverty, health situations, and out-of-pocket healthcare expenditure of the country and is foreseen to be of big help in attaining the objectives of Healthy Philippines 2022. Aside from microfinance, health loans and microinsurance can also help reduce healthcare costs.

\subsection{Damages, Disaster Management and Healthcare}


Disasters are regarded as an obstacle to long-term growth (United Nations International Strategy for Disaster Reduction, 2015). Earthquakes, large-scale flooding, and typhoons have been affecting countries like Japan, the Philippines, and Thailand. Onuma et al. (2017) conducted a study that assessed the effect of a country's own past disaster experiences and nearby countries' past experiences on subsequent disaster damage. A significant difference in the adaptation impact depending on the level of economic development as past disaster damage has a reducing effect on future disaster damage has been found. Natural disasters mitigate potential harm due to a country's own experiences, but the marginal impact is greater for lower-income countries. In terms of neighboring countries' disaster experiences, there is an adaptation effect that decreases natural disaster casualties, although the marginal impact was higher for higher-income countries. Furthermore, the study's findings reveal a combination of disaster types and country characteristics, indicating that disaster experiences in their own country and neighboring countries have not resulted in learning. Discussions on matters concerning disaster risk are vital to the global agenda as reflected in the Sustainable Development Goals (SDGs) and the Sendai Framework for Disaster Risk Reduction (SFDRR) 2015-2030 (Mochizuki \& Naqvi, 2019). According to Mochizuki and Naqvi (2019), disaster risk should be reflected metrics like the Risk-adjusted Human Development Index (RHDI). An RHDI is created by combining publicly accessible national-level datasets of disaster risk to public and private assets (such as health, educational services, and private housing) with an estimation of health, education, and capital formation spending. The study's insight shows that RHDI estimates revealed significant risk variations across HDI classes and geographic regions, with smaller islands and highly exposed countries in the Asia Pacific and Central America posing the greatest risk in terms of public spending and gross investment. The relative disaster risk to health, education, and other facilities was found to be the most variable in countries with a medium HDI, whereas low HDI countries were found to face on average lower relative risk than other HDI groups. Disaster risk is projected to increase in the coming decades as a result of socio-economic development and climate change unless adequately addressed.

According to Hallegatte (2015), the welfare impact of a disaster is not solely determined by the event's physical features or direct consequences in terms of lost lives and property. The rebuilding will be more or less complicated, and the welfare consequences will be smaller or greater, depending on the economy's ability to cope, heal, and rebuild. Furthermore, resilience was introduced as an important parameter to estimate the overall vulnerability of a population. It was divided into two components: instantaneous resilience, which is the ability to reduce the extent of an immediate loss of income over a given amount of capital losses, and dynamic resilience, which is the ability to rebuild and recover rapidly. Yezer (2017) shows that modeling disaster expectations is important as any resulting changes are indicators of economic effects when natural disasters occur. By creating three disaster expectation models, he concluded that the economic effects of a disaster depend not only on the damages incurred but also the extent to which the disaster event and the associated damage were anticipated. It was emphasized that it is not possible for the firms and households to insure against the economic losses, therefore, public policy takes a role for post-disaster aid wherein it focuses on unanticipated disaster events. Provision of generous relief from damages lowers the expectation of loss from disasters as the economic reaction will depend on both the changes in disaster expectations including the probability of loss.

In connection, Kim and Marcouiller (2015) examined the vulnerability and resiliency of 10 tourism-based regional economies in the US that are affected by several natural 
disasters. Natural disasters were shown to have a negative impact on regional economies in terms of physical harm and human loss. Prior to natural disasters, areas with stronger economies have relatively lower catastrophe losses than those with weaker economies. To reduce catastrophe losses, more effort must be put into improving regional economic conditions prior to natural disasters. While the findings of Xie et al. (2018) indicate that resilience measures could have reduced GDP losses from the Wenchuan earthquake in China by 47.4 percent between 2008 and 2011 by speeding up the recovery process, and could have further reduced losses by one year by shortening the recovery period. Furthermore, shortening the recovery period is not nearly as successful as rising restoration expenditure levels and steepening the recovery time path.

Mahapatra et al. (2018) examined the trend in extreme weather event-related mortality reported in India during 2001-2014. During the timeframe, 25\% of accidental deaths due to natural causes such as extreme precipitation and tropical cyclones declined over time whereas lighting and extreme temperature conditions showed an increasing trend. The study suggests that people are adaptive to cold waves and cyclones. On the other hand, heatwaves and extreme precipitation seem to be less. It recommends that fatalities due to extreme weather events may be reduced by building awareness on the adaptive mechanisms and a community-centered alert system. Fankhauser and McDermott (2014) analyzed the link between income and adaptation to climate events theoretically and empirically, it was highlighted that poor countries are more heavily affected by extreme weather events and future climate change than rich countries. One of the reasons for this is called 'adaptation deficit' wherein it limits poorer countries to adapt due to factors such as demand effect, whereby the demand for the climate security increases with income and efficiency effect, which works as a spill-over effect on the supply side. It was emphasized that adaptation productivity in rich countries is enhanced because of better public services and stronger institutions. The study uses panel data from the Munich Re natural catastrophe database and it found strong evidence for a demand effect for adaptation to climate extreme events such as floods and tropical cyclones and evidence on the efficiency effect is more uncertain. This implies that more data is necessary to further understand the adaption efficiency; in terms of policy, it concludes that inclusive growth policies should be an important factor for institutions to close the adaptation deficit.

Schumacher and Strobl (2011) focused on investigating the relationship between losses due to natural disasters, the country's exposure to different levels of natural hazard, and the levels of economic development. It has been found that to reduce possible losses, increasing wealth will not be substantial. Instead, the country's exposure to natural calamities is an important factor. The study suggests that it is important to have as much information as possible and gather enough data that concerns current and future hazards to be able to formulate a policy that is adaptive to the hazard situation of the country and help further prevent excessive losses.

The study of Khan et al. (2019) show that floods, storms, net forest loss, and a country's per capita income all increase external migration, while improvements in health spending invert migrants' decision to remain in their current place, also the mentioned factors have a negative impact on a country's economic resources, such as increased healthcare costs, high energy demand, and low economic growth. It was also able to show that there is an increase in healthcare spending and energy demand decreases poverty headcount while poverty incidence and mortality rate negatively influenced healthcare expenditures. 
Physical trauma, acute disease, and emotional trauma are the direct impact of disaster to the health of the population; disaster may also increase morbidity and mortality through its impact on the health care system (Giorgadze et al., 2011). Previous researches prove that natural disasters provide the catalyst for acts of terrorism. By the use of data from the Philippines, Turkey, and United Kingdom between 1987-2013, the study of Fisher and Dugan (2019) argues that government responses on natural disasters could alter the rational motivations for terrorism and by responding adequately, it can reduce both political violence risks and public health harms. It emphasizes that the government's response to natural disasters impacts subsequent terrorism rather than the natural disaster itself, therefore, the government must take advantage of the unique opportunity to diminish the incentives for terrorism when disasters occur.

One of the main barriers to accessing healthcare post-disaster was the lack of funds for medical consultation and transportation costs (Espallardo et al., 2015). In the week preceding Typhoon Haiyan's November 2013 landfall in the central Philippines, 66\% of their respondents reported they had no money for transportation or medical consultations. In this study, community insurance was the most used source of health financing at the local level. PhilHealth and a few of the government's health programs have policies that mandate eligible individuals to be made instant recipients at the point of admission to the healthcare system and a no-balance-billing policy that requires no other fees be charged or paid by eligible patients in the hospital. This policy helps public health facilities as they have minimal out-of-pocket payments during such periods. Results show a mean of healthcare costs higher than the household income indicating a catastrophic health expenditure.

If the national government is to be the primary provider of social safety nets in the aftermath of a catastrophe, frameworks for implementation, as well as the amount of funding needed to reduce catastrophic health costs, must be calculated correctly. Following a catastrophe, states increase program spending while receiving further federal transfers. Total tax collections are unaffected by disasters, but variations in sales, profits, and property tax revenues are amplified; disaster-induced additional spending is largely financed through federal transfers, which include both disaster relief funds and nondisaster-related public service assistance (Miao et al., 2016).

With a total of 674 disasters which were mainly floods, storms, and earthquakes that occurred in 2004-2017, significant poor physical health outcomes among the displaced population compared to the nondisplaced population (Jang et al., 2020). This study introduced the Sendai Framework for Disaster Risk Reduction 2015-2030 wherein researchers and policymakers must increase resources toward preventing and mitigating health outcomes. Furthermore, the study of Peters et al. (2019) claims that governments have been hesitant to invest sufficiently in programs that reduce the threats and impacts of disasters and emergencies. Nonetheless, they devote a significant amount of time, effort, and lots of money responding to emergencies, particularly high-impact disasters. They addressed the economic and social importance of health emergency and disaster risk management (EDRM) programs, as well as the viability of institutional alternatives for implementing these common goods for health that improve national health security.

\section{Method}

The study aimed to determine whether death, amount of damages caused by natural disasters and the country's exposure to such has a significant effect on the government's 
expenditure on disaster management and healthcare. This study used a quantitative approach to meet its objectives since numerical data were used to quantify the variables. The data collected are time-series in nature and according to Salkind (2012), time-series analysis is a statistical method appropriate for longitudinal research designs that involve research units that are measured repeatedly at regular intervals over time. This can provide an understanding of the underlying naturalistic process and the pattern of change over time, or it can evaluate the effects of either a planned or unplanned intervention. The research was performed and conducted in the Philippines. In consideration of the data available, the study tested data from 1991-2020.

The budget of the Department of Health and the Calamity Fund were used to quantify the government's expenditure on healthcare and expenditure on disaster management respectively. The number of tropical cyclones and earthquakes were combined to quantify exposure; the number of deaths and economic losses due to natural disasters to quantify damages. Recorded earthquakes only with a magnitude of 6.0 and above were considered for this study because according to the Richter scale, earthquakes with magnitudes 6.0 and above were the only ones capable of causing destruction; those with magnitude 7.5 are at the lower limit of major earthquakes (Richter, 1935). Data were sourced from various government agencies in the Philippines including the Department of Budget and Management, Department of Health, Philippine Atmospheric, Geophysical and Astronomical Services Administration, Philippine Institute of Volcanology and Seismology, including international agencies like the Institute for Health Metrics and Evaluation, and Emergency Events Database (EM-DAT).

Regression analysis was performed to determine the relationship between variables, to make sense out of that relationship, and provided predictive data based from the relationship that is established; multiple regression analysis was used to identify the changes in the dependent variable given the simultaneous changes with the independent variables (Uyanik \& Güler, 2013). A multiple regression model was formulated as follows:

$$
y=\beta_{0}+\beta_{i} x_{i}+\ldots+\beta_{n} x_{n}+e
$$

Where $y$ is the dependent variable, $x_{i}$ as the independent variables, $\beta_{i}$ as parameters, and $e$ for standard error. For this study, the independent variables are the deaths (DEATHS), log amount of economic damages (L_AOD) in US Dollar caused by natural disasters, and the number of natural calamities (EXPOSURE). Meanwhile, the dependent variables are the log of government expenditure on healthcare ( $\left.L_{-} H C E\right)$ and log of disaster management $\left(L_{-} D M E\right)$, both in Philippine Peso. Given that there are two dependent variables, separate multiple regression analyses were conducted. The models are:

$$
\begin{aligned}
& L_{-} D M E=\beta_{0}+\beta_{1} D E A T H S_{i}+\beta_{2} L_{-} A O D_{1}+\beta_{3} E_{\text {XPOSURE }}+e \\
& L_{-} H C E=\beta_{0}+\beta_{1} D E A T H S_{i}+\beta_{2} L_{-} A O D_{i}+\beta_{3} E X P O S U R E_{i}+e
\end{aligned}
$$

Budhdeo et al. (2015) utilized multivariate regression analysis to determine the impact of the decrease in government spending to health outcomes in European countries. With this study, a multivariate regression analysis was used to determine if deaths, socio-economic damages, and exposure have an impact on the government's expenditure on disaster management and healthcare.

\subsection{Augmented Dickey-Fuller (ADF)}


Most economic time series data have unit roots which show that their means and variances are not time-invariant. In such a case, a univariate series is said to be nonstationarity and cannot be used for regression with other non-stationary univariate series because of the risk that their results may be spurious. The only exception to this rule is when the time series data of all variables have identical unit roots.

The widely used unit root test is the so-called Augmented Dickey-Fuller (ADF) test. The basic equation for testing the stationarity of a time series is given by the following:

$$
\Delta x=\alpha_{o}+\alpha_{1} t+\beta x_{t-i}+\Sigma \varphi \Delta x_{t-i}+\varepsilon t
$$

where the first difference of the series, $\Delta \mathrm{x}_{\mathrm{t}}$, is regressed against lagged of its original level series, time, and lagged values of itself. If the estimated value of $\beta$ is more negative than MacKinnon critical values, the series is said to be stationary. Otherwise, it is considered to be non-stationary and has a unit root. The augmented portion of the test is to correct for any serial correlation in the variable.

\subsection{Optimal Lag Length}

An efficient test in determining the optimal lag length is to minimize the Akaike Information Criterion (AIC), Schwarz Information Criterion (SIC), or Bayesian Information Criterion (BIC) for each lag length on a trial-and-error basis. For the Akaike Information Criterion (AIC) which is a popular test, the formula is as follows:

$$
\ln A I C=(2 \mathrm{k} / \mathrm{n})+\ln (R S S / n)
$$

where $\mathrm{k}$ is the number of regressors including intercept, $\mathrm{n}$ is the number of observations, and RSS is the regression sum of squares. After experimenting with a sufficient number of lags in the model, the one which produces the smallest AIC would indicate the appropriate or optimal lag length.

\subsection{Structural Stability test}

Structural stability test refers to the stability of the coefficients of a regression model between different time periods. In this study, such test will be performed using Chow Breakpoint Test. A structural change could mean a change in the intercept, a change in the slope coefficients, or a change in both the intercept and slope coefficients. Either way, the results would imply structural instability and the model, therefore, cannot be used for policy analysis and forecasting.

The formula for testing the structural stability of the regression parameter involving time series data is as follows:

$$
F=\frac{\left(R S S_{R}-R S S_{U R}\right) / k}{R S S_{U R} /\left(n_{1}+n_{2}-2 k\right)}
$$

where $\mathrm{k}$ is the number of regressors including intercept, $\mathrm{n}$ is the number of observations, $\mathrm{RSS}_{\mathrm{R}}$ is the regression sum of squares restricted, and RSS ${ }_{U R}$ is the regression sum of squares unrestricted. If the computed F-statistic exceeds critical value, there is structural instability. Otherwise, the model is said to be structurally stable. 


\subsection{Test for Heteroskedastic Disturbances}

If the variance of the regression residuals of the model is time-varying, the parameters and their standard errors are said to be biased and inefficient. This condition is known as heteroskedasticity and if uncorrected could lead to wrong conclusions and decisions on the part of the investigator. To detect the presence of heteroskedastic disturbances in the residuals, the White Heteroskedasticity Test will be used.

$$
u^{2}=\alpha_{o}+\alpha_{1} X_{1}+\alpha_{2} X_{2}+\alpha_{3} X_{3}+\alpha_{4} X_{1}^{2}+\alpha_{5} X_{2}^{2}+X_{3}^{2}+\alpha_{6} X_{1} X_{2}+\alpha_{7} X_{1} X_{3}+\alpha_{8} X_{2} X_{3}+v t
$$

where $\mathrm{u}^{2}$ is the squared regression residuals regressed against the explanatory variables, their squares, and cross products.

\subsection{Johansen Cointegration Test}

In applying the Johansen Cointegration Test which consists of five options, although options 1 and 5 are avoided because of their explosive values which are not consistent with economic realities, such options were utilized according to the Dickey-Pantula principle by beginning with the most restrictive (Option 2) down to the least restrictive (Option 4).

If the computed trace statistics and maximum-eigenvalue statistics exceed their critical values, then there is cointegration among the variables. The hypothesized relationships cannot be deemed spurious and therefore genuine equilibrium relationships existed.

\subsection{Specification Error Test}

The Ramsey regression equation specification error test (RESET) will be used to test whether non-linear combinations of independent variables help in explaining the dependent variable. This will also help determine if there is no misspecification error in the data used in the study.

A Specification error test is associated with the specification of the model regarding the inclusion of an irrelevant variable, the exclusion of relevant variables, or the functional form of the model. A Specification error creates biased or inconsistent regression estimators, and the inconsistency can still be there even when the sample observation increases. To determine the specification of the model, this study used the equation:

$$
\hat{Y}_{i}=\hat{\beta}_{1}+\hat{\beta}_{2} X_{2 i}+\hat{\beta}_{3} X_{3 i}+\gamma \hat{Y}_{i}^{2}
$$

\subsection{Autocorrelation Test}

To determine whether the data suffers from excessive autocorrelation, the DurbinWatson test is to be used. The Durbin-Watson index provides insight on the residual correlation of the data: if the Durbin-Watson statistic is close to 2, this would mean that the series is free of correlation at a specific significance level. One limitation of this statistical test is that it is deemed ineffective when used against cross-sectional data. However, given that the data to be utilized in this research is time-series in nature, the use of Durbin-Watson index is recommended.

\section{Results}


Variable L_DME or the government's expenditure on disaster management is measured through Calamity Fund, sourced from the Philippines' Department of Budget and Management. Based on the data, no evident trend can be inferred for L_DME. In the aftermath of Typhoon Yolanda's devastation in late 2013, the government increased its spending for disaster risk reduction, bringing the data to its highest point in 2016. Investments in disaster risk management have boosted the resilience of populations for the most vulnerable to disasters. The National Disaster Risk Reduction and Management Fund's 2016 budget has also been nearly tripled, to P38.9 billion, from P14 billion in 2015. The increase in budget is because P19 billion of total risk reduction allocation would go to the Yolanda Rehabilitation and Recovery Fund as rehabilitation operations in areas devastated by Typhoon Yolanda continue. However, a change of administration caused a big drop in the NDRRMC budget from 2016 to 2017. The National Disaster Risk Reduction and Management Council (NDRRMC) Fund, commonly known as the Calamity Fund, received only P15.7 billion from the Duterte government. This is a drop of P23 billion from the Aquino administration's P38.9 billion in 2016.

The government's expenditure on healthcare or L_HCE is measured through the Department of Health's (DOH) budget. An uptrend can be seen in the dataset and no significant fluctuations are present. The data was sourced from the same department.

Deaths caused by tropical cyclones and earthquakes and their secondary phenomena which include flooding, landslides, heavy monsoon rains, and drought, show no consistent trend and include significant upticks from the year 2005 to year 2015. Data for such variables were sourced through the international disasters database, Emergence Events Database or EM-DAT, and the Philippine Statistics Authority (PSA). The highest point in the time series was in 2013, when Super Typhoon Haiyan, also known as Super Typhoon Yolanda, made landfall in the Philippines and devastated the whole country on November 8, and a 7.2 magnitude earthquake struck Bohol in October, resulting in a total of 7,056 deaths. A spike was observed for the year 2011 when the country was hit by Tropical Storm Sendong in December. Another significant increase was in 2006 where 1,418 deaths, with 1,168 from meteorological causes, 186 from geophysical causes, and 64 from hydrological causes. The year 2014, on the other hand, saw the fewest deaths, with only 23 casualties. There were 12,097 fatalities in the Philippines between 2010 and 2019.

The log Amount of Damages (1_AOD), in US dollar, accounts for the economic losses incurred due to the happening of the selected natural disasters. Data was sourced from EM-DAT. Generally, data shows an inconsistent trend with several significant peaks and troughs. The lowest point of the time-series data was shown in 1995 with only USD 53,600 socio-economic losses. The peak of the time-series was in 2013 when USD 1.2 billion amount of damages due to Typhoon Yolanda was recorded and a 7.2 magnitude earthquake happened in Bohol. It is evident in the time-series data that the amount of damages due to natural disasters is relatively higher in the years from 2010-2020 compared to the earlier years of the trend. From 2010-2019, the damages incurred were at PHP 463 billion and $62.7 \%$ accounts for the agricultural sector, followed by infrastructures with $23 \%$ and the private and communications sector with $14.3 \%$.

The exposure of the country to natural disasters is measured through the combined number of earthquakes and tropical cyclones annually and are represented as variable EXPOSURE in both econometric models. Sources for the data are Philippine Institute of Volcanology and Seismology and Philippine Atmospheric, Geophysical and Astronomical 
Services Administration respectively. No consistent trend was established as per the time series plot of the combined statistics.

The highest peak in the time series plot for Earthquakes is in 2012. In the same year, as reported by Phivolcs, a magnitude 6.9 earthquake shook the parts of the Western Visayas including the islands of Negros and Cebu. With a high destructive intensity VIII, total damage to infrastructure alone was recorded at PHP 383 million. Landslides that occurred in Solongon and Planas resulted in 51 casualties, 112 injuries, and 62 missing. Aside from this, tsunami waves as high as 5 meters occurred in certain areas which also caused damages in infrastructure. The highest peak in the time series plot for tropical cyclones before it plateaued is year 2018 where on the 15th of September, Typhoon Ompong, with the international name Mangkhut, made its landfall in Cagayan. This typhoon is considered to be the most destructive storm to hit the Philippines since Yolanda (international name Haiyan) hit the Philippines in 2013. As per PAGASA report as of September 20, 2018, an estimated PHP 16.7 billion worth of damages to infrastructure and agriculture in regions 1 to 2 and CALABARZON were recorded, alongside 8 casualties, 21 injuries, and 2 missing persons as per NDRRMC record.

The following are the regression analyses and diagnostic tests conducted:

Table 1: Augmented-Dickey Fuller Test (ADF)

\begin{tabular}{lllllll}
\hline Variable & Level & Prob & $\begin{array}{l}\text { 1st } \\
\text { Difference }\end{array}$ & Prob & $\begin{array}{l}\text { 2 }^{\text {nd }} \\
\text { Difference }\end{array}$ & Prob \\
\hline DEATHS & -6.076072 & 0.0001 & -9.057930 & 0.0000 & -4.230389 & 0.0154 \\
EXPOSURE & -4.509585 & 0.0063 & -9.105321 & 0.0000 & -5.984504 & 0.0003 \\
L_AOD & -5.066909 & 0.0017 & -10.45089 & 0.0000 & -8.439527 & 0.0000 \\
L_DME & -2.203567 & 0.4688 & -4.709096 & 0.0041 & -10.52750 & 0.0000 \\
L_HCE & -1.490131 & 0.8098 & -5.167244 & 0.0030 & -6.338986 & 0.0010 \\
\hline
\end{tabular}

Table 2: Regression Analysis (Dependent Variable: L_DME) Sample: 1991-2020

\begin{tabular}{lllll}
\hline Variable & Coefficient & Std. Error & t-Statistic & Prob. \\
\hline Constant & 17.48791 & 1.721926 & 10.15602 & 0.0000 \\
DEATHS & $-8.12 \mathrm{E}-05$ & 0.000119 & -0.684735 & 0.4996 \\
L AOD & 0.252317 & 0.116895 & 2.158493 & 0.0403 \\
EXPOSURE & 0.002360 & 0.010762 & 0.219265 & 0.8282 \\
\hline R-squared & 0.203886 & & \\
Adjusted R-squared & 0.112026 & Durbin-Watson stat & 0.647032 \\
F-statistic & 2.219542 & & & \\
Prob(F-statistic) & 0.109758 & & & \\
\hline
\end{tabular}

Table 3: Breusch-Godfrey Serial Correlation LM Test Null hypothesis: No serial correlation at up to 1 lag

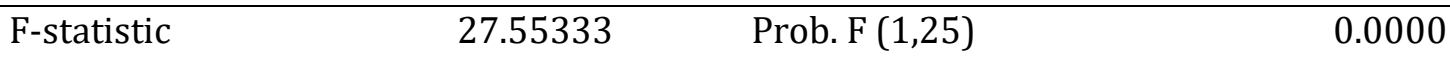


Table 4: Variance Inflation Factors

\begin{tabular}{ll}
\hline Variable & Centered VIF \\
\hline DEATHS & 1.328659 \\
L AOD & 1.614413 \\
EXPOSURE & 1.250952 \\
\hline
\end{tabular}

Table 5: Heteroskedasticity Test: Breusch-Pagan-Godfrey Null hypothesis: Homoskedasticity

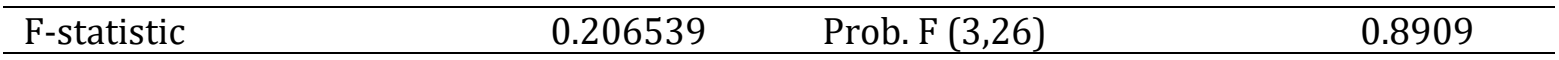

Table 6: Ramsey RESET Test

\begin{tabular}{llll}
\hline & Value & df & Probability \\
\hline t-statistic & 1.604263 & 25 & 0.1212 \\
F-statistic & 2.573660 & $(1,25)$ & 0.1212 \\
Likelihood ratio & 2.939554 & 1 & 0 D8 64 \\
\hline
\end{tabular}

Table 7: Chow Breakpoint Test: 2005

Null Hypothesis: No breaks at specified breakpoints

\begin{tabular}{llll}
\hline F-statistic & 3.130921 & Prob. F $(4,22)$ & 0.0351 \\
\hline
\end{tabular}

Table 8: Johansen Cointegration Test

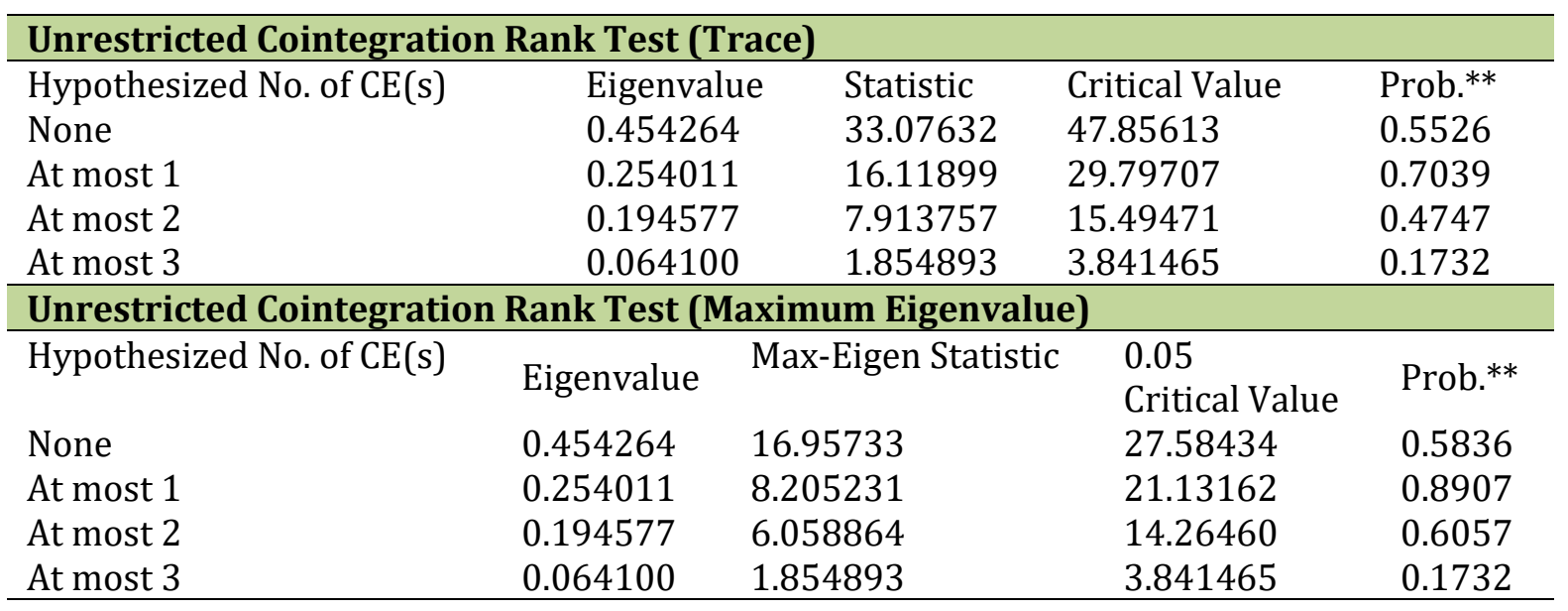

Table 9: Regression Analysis

Dependent Variable: L_HCE

\begin{tabular}{lllll}
\hline Variable & Coefficient & Std. Error & t-Statistic & Prob. \\
\hline Constant & 18.11745 & 1.280693 & 14.14660 & 0.0000 \\
DEATHS & -0.000212 & $8.82 \mathrm{E}-05$ & -2.399847 & 0.0239 \\
L AOD & 0.325099 & 0.086941 & 3.739291 & 0.0009 \\
EXPOSURE & 0.009260 & 0.008004 & 1.156824 & 0.2579 \\
\hline R-squared & 0.478134 & & \\
Adjusted R-squared & 0.417918 & Durbin-Watson stat & 1.061546 \\
F-statistic & 7.940398 & & & \\
\hline
\end{tabular}


\begin{tabular}{ll} 
Prob(F-statistic) $\quad 0.000639$ \\
\hline
\end{tabular}

Table 10: Breusch-Godfrey Serial Correlation LM Test

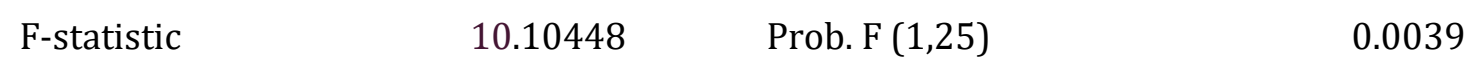

Table 11: Variance Inflation Factors

\begin{tabular}{ll}
\hline Variable & Centered VIF \\
\hline DEATHS & 1.328659 \\
L AOD & 1.614413 \\
EXPOSURE & 1.250952 \\
\hline
\end{tabular}

Table 12: Heteroskedasticity Test: Breusch-Pagan-Godfrey

$\begin{array}{llll}\text { F-statistic } & 0.310528 & \text { Prob. F }(3,26) & 0.8176\end{array}$

Table 13: Ramsey RESET Test

\begin{tabular}{llll}
\hline & Value & df & Probability \\
\hline t-statistic & 2.747860 & 25 & 0.0110 \\
F-statistic & 7.550736 & $(1,25)$ & 0.0110 \\
Likelihood ratio & 7.917725 & 1 & 0.0049 \\
\hline
\end{tabular}

Table 14: Chow Breakpoint Test: 2005

Null Hypothesis: No breaks at specified breakpoints

\begin{tabular}{llll}
\hline F-statistic & 7.542797 & Prob. F $(4,22)$ & 0.0006 \\
\hline
\end{tabular}

Table 15: Johansen Cointegration Test

\begin{tabular}{|c|c|c|c|c|}
\hline \multicolumn{5}{|c|}{ Unrestricted Cointegration Rank Test (Trace) } \\
\hline Hypothesized No. of CE(s) & Eigenvalue & Statistic & Critical Value & Prob.** \\
\hline None & 0.542031 & 39.78852 & 47.85613 & 0.2302 \\
\hline At most 1 & 0.352903 & 17.92181 & 29.79707 & 0.5719 \\
\hline At most 2 & 0.184809 & 5.734556 & 15.49471 & 0.7266 \\
\hline At most 3 & 0.000472 & 0.013228 & 3.841465 & 0.9082 \\
\hline \multicolumn{5}{|c|}{ Unrestricted Cointegration Rank Test (Maximum Eigenvalue) } \\
\hline Hypothesized No. of CE(s) & Eigenvalue & Statistic & 0.05 Critical Value & Prob.** \\
\hline None & 0.542031 & 21.86671 & 27.58434 & 0.2273 \\
\hline At most 1 & 0.352903 & 12.18726 & 21.13162 & 0.5293 \\
\hline At most 2 & 0.184809 & 5.721327 & 14.26460 & 0.6492 \\
\hline At most 3 & 0.000472 & 0.013228 & 3.841465 & 0.9082 \\
\hline
\end{tabular}

\section{Discussion}

As shown in table 9, there is a significant, negative relationship between deaths and government's healthcare expenditure whereas deaths increase, government's healthcare expenditure decreases. Findings of Wenzel and Wolf (2013) explains such phenomena the loss of human capital will reduce the production capacity of the economy, decreasing the financial capability to allocate more funds. The study of Budhdeo et al. (2015) showed that a slight decrease in healthcare spending also resulted in a small increase in mortality 
for all ages. Such findings, combined with the results of this paper, is suggestive of a possible cycle: increased deaths decrease healthcare spending, decreased healthcare spending increase deaths. This further emphasizes the need for the government to take necessary actions that can potentially decrease deaths by natural disasters given the possibility of a cycle. Therefore, the study recommends the improvement of healthcare facilities specially that it was found that conducive healthcare facilities that can perform medical disaster response are necessary to lessen deaths since it is highly possible that it is first contact between an individual and health care during critical need in the midst of disasters (Wenzel \& Wolf, 2013). Although contradicting previous studies like the study of Heijink et al. (2012) that states that the increasing rates of deaths will lead to the rise of healthcare spending, the relationship is vital to decide if allocating more resources to the healthcare industry is worthwhile, as well as whether private healthcare investment should be encouraged from a policy standpoint. Investing in health institutions, such as hospitals and clinics, is critical for health outcomes in any country regardless of their class (Bein et al., 2017).

The regression analysis shown in table 9 shows a significant, positive relationship between the amount of damages and the healthcare expenditure of the government was shown in the results. This emphasizes that government or concerned agencies consider the socio-economic damages incurred when preparing their budgets. Government must take advantage of the unique opportunity to diminish the further damages when disasters occur. Their response to natural disasters impacts subsequent damaging factor like terrorism rather than the natural disaster itself (Fisher \& Dugan, 2019). Results are, however, contrary to the findings of Khan et al. (2019) that loss from natural disaster will have a negative impact on a country's economic resources because of the increased healthcare spending with the anticipation of lower poverty headcount.

Results shown in table 2 demonstrates disaster management expenditure as a function of the amount of damages where a significant, direct relationship exists between the two. As the amount of damages incurred from natural events is established, the post-disaster aid will not only cover relief and rehabilitation but will also focus on the projects for the unanticipated disaster events; economic implications of a disaster are determined not only by the damages incurred, but also by the extent to which the catastrophic occurrence and associated harm were foreseen, achieving the objective of lowering the loss from natural disasters in the future (Yezer, 2017).

The country's exposure to natural disasters is insignificant in determining both the healthcare and disaster management expenditure of the government, as illustrated in tables 9 and 2, respectively. Meanwhile, as indicated in table 2, deaths are deemed insignificant as well in determining the disaster management expenditure of the government. The findings of Onuma et al. (2017) show that a country's disaster experiences and its neighbors' have not resulted in learning, despite their extreme exposure to natural disasters. On the other hand, the study of Howe and Bang (2017), which specifically focused on Philippines and Malaysia after the occurrence of Typhoon Haiyan and Cyclone Nagris, concluded that national resilience and government preparedness were insufficient despite its increased exposure to natural disasters. Samaritan's Dilemma, a term coined by Buchanan (1972), explains that altruism of the benefactor may result in adverse behavior of the beneficiary. A country suffers from such if when given foreign aid, ex-ante protection and ex-post relief is impacted negatively (Cohen \& Weker, 2008) after major storm events, an increased level of previous foreign 
aid increased mortality rates with increased probability of non-zero deaths due to floods and earthquakes (Raschky, 2008).

Although in studies where exposure and disaster management expenses exhibit a significant relationship, it was found that adaptation impact varies significantly depending on the level of economic development, as past disaster damage has a decreasing effect on future catastrophe damage (Onuma et al., 2017). This demonstrates that exposure may affect disaster management expenditure depending on the result of the impact of a country's own historical catastrophe experiences, as well as the experiences of adjacent countries, on subsequent disaster damage. In addition, poor countries are more heavily affected than rich countries by extreme weather events and future climate change (Fankhauser \& McDermott, 2014). This is linked to the 'adaptation deficit,' which limits poorer countries' ability to adapt due to variables such as the demand effect, in which demand for climate security rises as income rises, and the efficiency effect which serves as a supply-side spill-over externality. It is emphasized that in rich countries, productivity is increased as a result of improved public services and stronger institutions.

Despite being highly exposed to typhoons and earthquakes, there is an underinvestment in disaster management funds because the Philippines, as a developing country, is heavily relying on foreign aid (Gaiha et al., 2012). Since post-World War II, the Philippines has been receiving foreign aid for their economic recovery, and their absorptive capacity is strengthened by their major donors such as the United States, China, and their largest donor, Japan. These countries are motivated to provide aid because of direct and shortterm political and economic benefits. For instance, Japan gains benefits from giving assistance by promoting Japanese business in the recipient countries. It is also used to support conflict resolution and peace consolidation for the security of their people living in the recipient countries (Kang, 2010). Given such a situation, it is important for the government to make sure that foreign aid works for the benefit of the country. Despite the presence of major donors and the availability of help, there should be a conscious effort from the government to make sure that foreign aids are effectively used and does not result in the regression of the government's own policies and practices in terms of disaster management.

The result of the first regression analysis in table 2 implied that $20.4 \%$ of the possible changes in the disaster management expenditure can be explained by its regressors while the second regression analysis, table 9, showed that $47.8 \%$ of potential changes in healthcare expenditure can be attributed to the dependent variables. Other factors that affect both dependent variables are economic development (Wenzel \& Wolf, 2013; Onuma et al., 2017), the role of institutions (Kahn, 2005), government stability (Raschky, 2008), educational attainment (Skidmore \& Toya, 2007), and economic inequality (Anbarci et al., 2005), and governance (Ahmad \& Hasan, 2016).

\section{Implications}

According to the Department of Budget and Management (DBM), budget adjustments are made because of the following reasons: enactment of new laws, adjustments in macroeconomic parameters, and changes in resource availability. Wenzel and Wolf (2013) claim that financial state and the economic development of a country are determinants of how much bigger or smaller a government can allot for disaster-related budgets; recovery period of human and capital assets, which affects the economy's income generation through productivity is also a factor that may help determine. Once the amount of 
damages is identified, ex-post disaster aid will go beyond relief and rehabilitation but will include prioritization of projects for unanticipated occurrence of disasters, potentially lowering damages incurred (Yezer, 2017). Despite the limitations brought about by other factors like limited resources, existing laws, and the like, the relationship that exists between healthcare and disaster management expenditure, and exposure, deaths, and socio-economic damages caused by natural disasters should not be disregarded thus should be considered in formulating policies.

Anttila-Hughes and Hsiang (2013) were able to conclude that for the average household, an estimate of $94 \%$ of the economic loss due to disaster comes from unearned income long after the occurrence of the disaster. In the New York attack on the $11^{\text {th }}$ of September 2001, Bram et al. (2002) estimated the value of lost human capital by adding the current incomes of the victim until retirement. This resulted in a total of USD 7.8 million lost. This study recommends that the Philippine government should use this method in assessing the total damages incurred post-disaster, including lost human capital to further understand the impact of natural disasters and make necessary adjustments.

The budgeting process in the Philippines, as presented by the Office of Ombudsman, includes four (4) stages namely Preparation, Legislation/Authorization, Execution, and Accountability. In the Preparation stage, the National Economic and Development Authority (NEDA) provides "overall economic assumptions" which will determine budgetary levels while the Department of Finance, together with the Bureau of Treasury, Bureau of Internal Revenue, and Bureau of Customs, identify sources of financing. Such macroeconomic assumptions include the Gross National Product (GNP), real growth rate, inflation rate, population growth, exchange rates, etc. Once the Development Budget Coordination Committee (DBCC) determined the economic targets, revenue forecast, and the financing plan and the President and the Cabinet give its approval, a Budget Call is issued by DBM. During this Budget Call, agencies are tasked to make their budget proposals in consideration of the limitations set. In the Preparation stage of the budgeting process is where the findings of the research can influence the decision-making process. During this stage in the budget process, agencies are to rank and prioritize projects and activities that can best support the goals of the agency. The members of the National Disaster Risk Reduction Management Council can focus on projects and/or activities that can reduce the amount of socio-economic damages caused by natural disasters. In other words, projects focused on preparation and resilience should be given as much prioritization, if not more, as projects focused on relief and rehabilitation. According to Schumacher and Strobl (2011), an increase in wealth and focusing on programs that can reduce the impact of disasters is not enough since the country's vulnerability is a major determinant of how the country will be impacted. Peters et al. (2019) claims that governments are hesitant to invest enough in programs that reduce the threats and impacts of disasters but instead devote a significant amount of resources responding to high-impact disasters. It has been found that resilience measures could have reduced GDP losses from the Wenchuan earthquake in China by 47.4 percent through faster recovery (Xie et al., 2018).

Community-based disaster risk reduction management should all adhere to standardized protocols and practices and should be scaled down to the local level for improved resilience, safety, and development of the community (Balgos, 2013). Mahapatra et al. (2018) recommend that in order to reduce fatalities due to extreme weather events, a community-centered alert system must be developed. Backed by the recommendation made by Chacko et al. (2019) stating that the local government should initiate immediate 
intervention through an incident command system, an emergency operation center, a well-structured local emergency management plan, and mutual aid agreements, both the national and local governments should work on improving disaster programs that largely includes better local responses. Marikina, a city prone to flooding, is an example that institutionalizing disaster risk management structures to the local level is possible; despite the limitations faced by the city because of legislation, lack of funds, and limited access to technology, Marikina improved its disaster risk management system and strengthened its local institution (Dangcalan et al., 2019). The Philippine DRRM Act of 2010 requires local government units to allot 5\% for calamity funds, $70 \%$ for disaster preparedness measures, and 30\% for response and recovery. However, most cities only spend $30 \%$ of the budget for disaster preparedness measures, and if the disaster is not highly catastrophic, $70 \%$ of the calamity fund will be reallocated to other projects or to fund bonuses of employees (Dariagan et al., 2020). It is recommended to scale down disaster management to the local level and promote the improvement of their own systems. The national government, however, through the Disaster Risk Reduction Management Council, should still oversee their operations and make sure that concerns and responsibilities are well addressed.

\section{Conclusion}

The objectives of the study to (1) evaluate the relationship of deaths and amount of damages caused by natural disasters and the number of natural calamities per year to the government's expenditure on disaster management and healthcare, (2) identify other factors that may affect the government's expenditure on healthcare and disaster management and (3) provide insights and recommendations that may aid in the policymaking of the government were achieved through the use of multiple regression analyses, extensive research on related literature, and analysis of existing policies in relation to the data results of the regression analyses and information from related studies, respectively.

After performing a quantitative analysis on the variables using the multiple regression method, findings demonstrate a positive association between disaster management spending and socio-economic losses, but no such relationship exists between disaster management spending, and deaths and exposure. Meanwhile, there is a negative association between healthcare spending and mortality, a positive relationship between healthcare spending and economic damages, and no relationship between healthcare spending and exposure. Furthermore, the result of the first regression analysis implied that $20.4 \%$ of the possible changes in the value of $I_{-} D M E$ can be explained by its regressors, $[A O O D, D E A T H S$, and EXPOSURE while the second regression analysis showed that $47.8 \%$ of potential changes from L_HCE can be rationalized by its regressors, $I_{-} A O D$, DEATHS, and EXPOSURE.

The results of the study suggest that (1) the amount of socio-economic damages caused by natural disasters has a direct effect to the disaster management expenditure of the government, (2), the number of deaths and the government's healthcare expenditure are inversely related (3), that socio-economic damages the government's healthcare expenditure exhibit a direct relationship, (4) deaths and exposure do not affect the government's spending on disaster management, and (5) exposure do not affect the government's spending on healthcare. 
Other factors that affect the dependent variables include economic development (Wenzel \& Wolf, 2013; Onuma et al., 2017), role of institutions (Kahn, 2005), government stability (Raschky, 2008) educational attainment (Skidmore \& Toya, 2007), and economic inequality (Anbarci et al., 2005), and governance (Ahmad \& Hasan, 2016).

Improvement of healthcare facilities that can perform medical disaster response, efficient utilization of foreign aid, the inclusion of unearned income and lost human capital in assessing damages, and the prioritization of projects focused on preparation and resilience including the improved involvement of local government units are the insights and recommendations made based on the results of the study.

\section{Acknowledgement}

This research would not be possible without the valuable work of the academics before us, the tremendous and unwavering support of our family, friends, professors, and of the Business Economics Department of the University of Santo Tomas. We'd also like to extend our heartfelt gratitude to our research adviser, Asst. Prof. Ronaldo R. Cabauatan, $\mathrm{PhD}$, for his constant guidance and motivation throughout our research. Above all, we thank the Almighty Father for giving us the strength and wisdom to complete this thesis.

\section{Funding}

This study received no funding.

\section{Conflict of Interests}

The authors declare no conflict of interest in this study.

\section{References}

Ahmad, R., \& Hasan, J. (2016). Public Health Expenditure, Governance and Health Outcomes in Malaysia. Jurnal Ekonomi Malaysia, 50(01). https://doi.org/10.17576/jem-2016-5001-03

Alcayna, T., Bollettino, V., Dy, P., \& Vinck, P. (2016). Resilience and Disaster Trends in the Philippines: Opportunities for National and Local Capacity Building. PLOS Currents Disasters, 1, 1-11. https://doi.org/10.1371/currents.dis.4a0bc960866e53bd6357ac135d740846

Anbarci, N., Escaleras, M., \& Register, C. A. (2005). Earthquake fatalities: The Interaction of Nature and Political Economy. Journal of Public Economics, 89(9-10), 19071933. https://doi.org/10.1016/j.jpubeco.2004.08.002

Anttila-Hughes, J. K., \& Hsiang, S. M. (2013). Destruction, Disinvestment, and Death: Economic and Human Losses Following Environmental Disaster. SSRN Electronic Journal, 1-86. https://doi.org/10.2139/ssrn.2220501

Aranas, L. L., Khanam, R., Rahman, M. M., \& Nghiem, S. (2020). Combining Microfinance and Health in Reducing Poverty-Driven Healthcare Costs: Evidence From the Philippines. Frontiers in Health, 8. https://doi.org/10.3389/fpubh.2020.583455

Balgos, B. (2013). From Typhoon Ondoy to the Unnamed Monsoon (2009-2012): Policy Reforms and Challenges in the Philippine Disaster Management System. Natural 
Disaster and Reconstruction in Asian Economies, 185-199. DOI:10.1057/9781137364166_12

Baquiran, J., Castillo, B., Chong, C. (2017). A cross-sectional descriptive study on the earthquake preparedness of selected highly vulnerable barangays in Metro Manila. UERM Health Sciences Journal, 6(1), 15-22.

Bein, M., Unlacan, D., Oluwu, G., Kalifa, W. (2017) Healthcare spending and health outcomes: evidence from selected East African countries. African Health Sciences, 247-254. doi: 10.4314/ahs.v17i1.30

Benson, C. (1997). The economic impact of natural disasters in the Philippines. Overseas Development Institute Working Papers 99. https://cdn.odi.org/media/documents/7026.pdf

Bram, J., Haughwout, A., \& Orr, J. (2002). Has September 11 affected New York City's growth potential? Modeling Spatial and Economic Impacts of Disasters, 8(2), 81-96. https://doi.org/10.1007/978-3-540-24787-6_4

Bredenkamp, C., Buisman, L. R. (2016). Financial protection from health spending in the Philippines: policies and progress. Health Policy Pelan, 31(7), 919-927. doi: 10.1093/heapol/czw011.

Buchanan, J.M. (1972): The Samaritan's Dilemma, reprinted in: Buchanan, J.M. (1977): Freedom in Constitutional Contract, Texas A\&M University Press: 169-185.

Budhdeo, S., Watkins, J., Atun, R., Williams, C., Zeltner, T., \& Maruthappu, M. (2015). Changes in government spending on healthcare and population mortality in the European Union, 1995-2010: A cross-sectional ecological study. Journal of the Royal Society of Medicine, 108(12), 490-498. https://doi.org/10.1177/0141076815600907

Chacko, S., Randolph, R., Morsch, G. (2019) Disaster Medicine: Public Health Preparedness for Natural Disasters. National Library of Medicine, FP Essent, 487, 17-22, PMID: 31799816

Cohen, C., Werker, E. (2008) The Political Economy of "Natural" Disasters. Journal of Conflict Resolution, 52(6), 795-819. https://doi.org/10.1177/0022002708322157

Dangcalan, R., Dela Cruz., R., Amparo, J., Jimena, C., Alviar, N., (2019). Designing a Disaster Resilient City: A Study of the Institutionalization Process of the Marikina City Disaster Risk Reduction and Management Office. International Journal of Sciences: Basic and Applied Research, 45(2), 64-82.

Dariagan, J. D., Atando, R. B. \& Asis, J. L. B. (2021). Disaster preparedness of local governments in Panay Island, Philippines. Natural Hazards: Journal of the International Society for the Prevention and Mitigation of Natural Hazards, 105, 1923-1944. https://doi.org/10.1007/s11069-020-04383-0

Dayrit, M. M., Lagrada, L. P., Picazo, O. F., Pons, M. C., \& Villaverde, M. C. (2018). The Philippines Health System Review. Health Systems in Transition, 8(2), 1-352. doi:978-92-9022-673-4

Doroteo, H. (2015, December). Disaster Risk Profile and Disaster Risk Management Framework of the Philippines: Natural Disasters. University of Oviedo - Department of Medicine Unit for Research and Emergency and Disaster. Conference: Erasmus Mundus Master in Public Health in Disasters. doi: 10.13140/RG.2.1.4656.3922

Emanuel, K. A. (2013). Downscaling CMIP5 climate models shows increased tropical cyclone activity over the 21st Century. Proceedings of the National Academy of Sciences, 110(30), 12219-12224. https://doi.org/10.1073/pnas.1301293110

Espallardo, N., Geroy, L. S., Villanueva, R., Gavino, R., Nievera, L. A., \& Hall, J. L. (2015). A snapshot of catastrophic post-disaster health expenses post-Haiyan. Western Pacific Surveillance and Response Journal, 6(1), 76-81. https://doi.org/10.5365/wpsar.2015.6.2.hyn_017 
Fankhauser, S., McDermott, T, (2014). Understanding the adaptation deficit: Why are poor countries more vulnerable to climate events than rich countries? Global Environmental Change, 27, 9-18, https://doi.org/10.1016/j.gloenvcha.2014.04.014

Ferreira, S., Hamilton, K., \& Vincent, J. R. (2013). Does development reduce fatalities from natural disasters? New evidence for floods. Environment and Development Economics, 18(6), 649-679. https://doi.org/10.1017/s1355770x13000387

Fisher, D., \& Dugan, L. (2019). The Importance of Governments' Response to Natural Disasters to Reduce Terrorist Risk. Justice Quarterly, 1-32. https://doi.org/10.1080/07418825.2019.1685120

Gaiha, R., Hill, K., Thapa, G., \& Kulkarni, V. S. (2015). Have Natural Disasters Become Deadlier? Sustainable Economic Development, 1, 415-444. https://doi.org/https://doi.org/10.1016/B978-0-12-800347-3.00023-6

Giorgadze, T., Maisuradze, I., Japaridze, A., Utiashvili, Z., Abesadze, G. (2011). Disasters and their consequences for public health. Georgian Med News, 194, 59-63. PMID: 21685525.

Hallegatte, S. (2015). The indirect cost of natural disasters and an economic definition of macroeconomic resilience, Policy Research Working Paper Series 7357, The World Bank.http://hdl.handle.net/10986/22238

Heijink, R., Koolman, X., \& Westert, G. P. (2012). Spending more money, saving more lives? The relationship between avoidable mortality and healthcare spending in 14 countries. The European Journal of Health Economics, 14(3), 527-538. doi:10.1007/s10198-012-0398-3

Howe, B. \& Bang, G. (2017). Nargis and Haiyan: The Politics of Natural Disaster Management in Myanmar and the Philippines. Asian Studies Review, 41, 58-78. 10.1080/10357823.2016.1265484.

Jang, S., Ekyalongo, Y., \& Kim, H. (2021). Systematic Review of Displacement and Health Impact From Natural Disasters in Southeast Asia. Disaster Medicine and Public Health Preparedness, 15(1), 105-114. doi:10.1017/dmp.2019.125

Jha, S., Martinez, A., Quising, P., Ardaniel, Z., \& Wang, L. (2018). Natural Disasters, Public Spending, and Creative Destruction: A Case Study of the Philippines. ADBI Working Paper Series., 817th ser., 1-30. http://dx.doi.org/10.2139/ssrn.3204166

Kahn, M. E. (2005). The death toll from natural disasters: The role of income, geography and institutions. The Review of Economics and Statistics, 87, 271-284. https://doi.org/10.2139/ssrn.391741

Kang, H. (2010). The Philippines Absorptive Capacity for Foreign Aid. Philippine Institute for Development Studies Discussion Paper Series No. 2010-15. http://hdl.handle.net/10419/126799

Khan, K. A., Zaman, K., Shoukry, A., Sharkawy, A., Gani, S., Sasmoko, S., Ahmad, J., Khan, A., \& Sanil, H. (2019). Natural disasters and economic losses: Controlling External Migration, energy and environmental resources, water demand, and financial development for Global Prosperity. Environmental Science and Pollution Research, 26(14), 14287-14299. https://doi.org/10.1007/s11356-019-04755-5

Kim, H., \& Marcouiller, D. W. (2015). Considering disaster vulnerability and resiliency: the case of hurricane effects on tourism-based economies. The Annals of Regional Science, 54(3), 945-971. https://doi.org/10.1007/s00168-015-0707-8

Knutson, T. R., McBride, J. L., Chan, J., Emanuel, K., Holland, G., Landsea, C., Held, I., Kossin, J. P., Srivastava, A. K., \& Sugi, M. (2010). Tropical cyclones and climate change. Nature Geoscience, 3(3), 157-163. https://doi.org/10.1038/ngeo779

Mahapatra, B., Walia, M., \& Saggurti, N. (2018). Extreme weather events induced deaths in India 2001-2014: Trends and differentials by region, sex and age group. Weather and Climate Extremes, 21, 110-116. https://doi.org/10.1016/j.wace.2018.08.001 
Mercado, R. M. (2016). People's Risk Perceptions and Responses to Climate Change and Natural Disasters in BASECO Compound, Manila, Philippines. Procedia Environmental Sciences, 34, 490-505. https://doi.org/10.1016/j.proenv.2016.04.043

Miao, Q., Hou, Y., \& Abrigo, M. (2016). Measuring the Financial Shocks of Natural Disasters: A Panel Study of U.S. States Professor of Public Administration and International Affairs (PAIA) Associate Directors. National Tax Journal, 71, 11-44. https://doi.org/10.13140/RG.2.2.29226.82889

Mochizuki, J., \& Naqvi, A. (2019). Reflecting Disaster Risk in Development Indicators. Sustainability, 11(4), 996. https://doi.org/10.3390/su11040996

Obermann, K., Jowett, M., \& Kwon, S. (2018). The Role of National Health Insurance for Achieving UHC in the Philippines: A Mixed Methods Analysis. Global Health Action, 11(1). doi:10.1080/16549716.2018.1483638

OECD. (2011). Classification of Health Care Financing Schemes (ICHA-HF). A System of Health Accounts 2011, 153-192. doi:https://doi.org/10.1787/9789264270985-en

Onuma, H., Shin, K.J. \& Managi, S. (2017). Reduction of future disaster damages by learning from disaster experiences. Nat Hazards, 87, 1435-1452. https://doi.org/10.1007/s11069-017-2825-3

Pailoplee, S., \& Boonchaluay, N. (2016). Earthquake activities in the philippines islands and the adjacent areas. Geosciences Journal, 20(6), 877-889. https://doi.org/10.1007/s12303-016-0017-x

Pelling, M., \& Dill, K. (2009). Disaster politics: Tipping points for change in the adaptation of sociopolitical regimes. Progress in Human Geography, 34(1), 21-37. https://doi.org/10.1177/0309132509105004

Peters, D. H., Hanssen, O., Gutierrez, J., Abrahams, J., \& Nyenswah, T. (2019). Financing Common Goods for Health: Core Government Functions in Health Emergency and Disaster Risk Management. Health Systems \& Reform, 5(4), 307-321. https://doi.org/10.1080/23288604.2019.1660104

Phaup, M., \& Kirschner, C. (2010). Budgeting for Disasters: Focusing on the Good Times. OECD Journal on Budgeting, 10(1), 1-24. doi:10.1787/budget-10-5kmh5h6tzrns

Rahman, M. M., Khanam, R., \& Rahman, M. (2018). Health care expenditure and health outcome nexus: New evidence from the saarc-asean region. Globalization and Health, 14(1). doi:10.1186/s12992-018-0430-1

Raschky, P. A. (2008). Institutions and the losses from natural disasters. Natural Hazards and Earth System Sciences, 8(4), 627-634. https://doi.org/10.5194/nhess-8-6272008

Raschky, P. A., \& Schwindt, M. (2016). Aid, catastrophes and the samaritan's dilemma. Economica, 83(332), 624-645. https://doi.org/10.1111/ecca.12194

Ray, K., Ghimire, J., \& BC, R. K. (2019). Effects of disaster on primary health care in low income countries. Journal of Nepal Health Research Council, 17(01), 1-8. doi:10.33314/jnhrc.v17i01.1688

Richter, C. F. (1935). An instrumental earthquake magnitude scale. Bulletin of the Seismological Society of America, 25(1), 1-32.

Rose, A. (2004). Economic principles, issues, and research priorities in hazard loss estimation. Modeling Spatial and Economic Impacts of Disasters, 13-36. https://doi.org/10.1007/978-3-540-24787-6_2

Salazar, M. A., Pesigan, A., Law, R., Winkler, V. (2016) Post-disaster health impact of natural hazards in the Philippines in 2013. Glob Health Action, 9(1). doi: 10.3402/gha.v9.31320.

Salkind, N. (2012). Time-Series Study. Encyclopedia of Research Design, 1, 1520-1528 doi:https://doi.org/10.4135/9781412961288.n465 
Schumacher, I. \& Strobl, E. (2011). Economic development and losses due to natural disasters: The role of hazard exposure. Ecological Economics, 72(C), 97-105. doi: https://doi.org/10.1016/j.ecolecon.2011.09.002

Schumpeter, J. A. (1962). The Process of Creative Destruction. In Capitalism, Socialism, and Democracy (3rd ed., p. 83). chapter, Harper Torchbooks.

Skidmore, M., \& Toya, H. (2012). Natural Disaster Impacts and Fiscal Decentralization. Land Economics, 89(1), 101-117. https://doi.org/10.3368/le.89.1.101

Strobl, E. (2019). The impact of typhoons on economic activity in the Philippines: Evidence From Nightlight Intensity. ADB Economics Working Paper Series, 589th ser., 1-28. doi:10.22617/wps190278-2

United Nations International Strategy for Disaster Reduction. (2015). UN System Task Team on the POST-2015 UN Development Agenda. United Nations. Retrieved January 23, 2022, from https://www.un.org/en/development/desa/policy/untaskteam_undf/thinkpieces /3_disaster_risk_resilience.pdf

Uyanık, G. K., \& Güler, N. (2013). A study on multiple linear regression analysis. Procedia - Social and Behavioral Sciences, 106, 234-240. https://doi.org/10.1016/j.sbspro.2013.12.027

Villacin, D. T. (2017). A Review of Philippine Government Disaster Financing for Recovery and Reconstruction. PIDS Discussion Paper Series, 2017-21, 1-51. doi:http://hdl.handle.net/10419/173598

Wannewitz, S., Hagenlocher, M., \& Garschagen, M. (2016). Development and Validation of a Sub-national Multi-hazard Risk Index for the Philippines. GI_Forum 2016, 1, 133140. doi:10.1553/giscience2016_01_s133

Wenzel, L., \& Wolf, A. (2013). Protection against major catastrophes: An economic perspective Paper No. 137. Hamburg Institute of International Economics Research. http://hdl.handle.net/10419/69624

Xie, W.,Rose, A., Li, S., He, J., Li, N., \& Ali, T. (2018). Dynamic Economic Resilience and Economic Recovery from Disasters: A Quantitative Assessment. Risk Analysis, 38(6), 1306-1318. https://doi.org/10.1111/risa.12948

Yezer, A. (2010). Expectations and Unexpected Consequences of Public Policy toward Natural and Man-Made Disasters. The Economics of Natural and Unnatural Disasters, 3, 39-64, DOI: 10.17848/9781441678812.ch3 